\title{
OS PARADIGMAS DE UMA EDUCAÇÃO PARA TODOS
}

\author{
Francine Alessandra Gracia Menna ${ }^{1}$ \\ Valdecy Corrêa Júnior ${ }^{2}$
}

\section{RESUMO}

Esta contribuição oportuniza reflexões sobre a temática de uma educação para todos, tanto na área do contexto educacional, como nos desafios enfrentados na formação de professores frente a diversidade em sala de aula. $O$ trabalho inicia-se com um breve acesso a termos relevantes para o conceito da educação escolar para todos, de modo a inserir o leitor neste paradigma educacional, que compreende ser o contexto educacional um espaço de debate, estilos e ritmos de aprendizagem. Abarca, portanto, os conceitos de educação para todos, em busca do reconhecimento do outro, do diálogo entre diferentes grupos sociais e culturais, que preconiza a construção de um projeto em que as diferenças se incorporem dialeticamente. Em última análise, o artigo mostra as perspectivas para o alcance da educação inclusiva, valorizando os profissionais da educação e respeitando a diversidade humana. Nesse contexto, são discutidos os atuais projetos de formação de professores, que são em uma estrutura de conhecimento enxuta, sem aprofundamento de conhecimentos que possibilite aos futuros professores a formação de um contexto amplo, com conteúdo direcionado a uma Educação para Todos

Palavras-chave: educação para todos, práticas educacionais, diversidade, políticas públicas

\section{ABSTRACT}

This contribution provides opportunities for reflections on the theme of education for all, both in the educational context, and in the challenges faced in teacher education in view of the diversity in the classroom. The work begins with a brief access to terms relevant to the concept school education for all, to insert the reader into this educational paradigm, which understands that the educational context is a space for debate, styles

\footnotetext{
1É Mestra em Ciências da Educação pela Faculdade Interamericana de Ciências Sociales (FICS). Possui Graduação em Pedagogia pela Universidade de Sorocaba (2002). É especialista em Educação Infantil (2005) e Psicopedagogia Clínica e Institucional (2007).

${ }^{2}$ Mestra em Ciências da Educação pela Faculdade Interamericana de Ciências Sociales (FICS). Possui Graduação em Artes Visuais pela Universidade Federal do Espírito Santo (2015). É especialista em Educação de Jovens e Adultos pela Unisudeste Ensino Superior (2017).
} 
and learning rhythms. Therefore, it encompasses the concepts of education for all, in search of recognition of the other, of dialogue between different social and cultural groups, which advocates the construction of a project in which differences are incorporated dialectically. Ultimately, the article shows perspectives for achieving inclusive education, valuing education professionals and respecting human diversity. In this context, the current teacher education projects are discussed, which are in a lean knowledge structure, without deepening knowledge that enables future teachers to form a broad context, with content aimed at of training teachers for Special Education, in perspective education for all

Keywords: education for all, educational practices, diversity, public policy

\section{INTRODUÇÃO}

Espera-se que este artigo contribua efetivamente para uma melhor compreensão da educação inclusiva, colaborando nas mudanças de paradigmas educacionais.

O estudo deste tema conduz numa reflexão e ação laboral, desenvolver e preparar as pessoas ao exercício de cidadania, garantindo seus direitos, desempenhando seus deveres e desenvolvendo as competências para o trabalho.

Sabe-se que o papel do professor é fundamental para uma educação de qualidade. Nesta perspectiva, desenvolver um trabalho voltado para construção de uma sociedade mais justa, democrática e solidária, respeitando as diferenças.

Através do paradigma da inclusão, há a necessidade em oportunizar uma formação de qualidade, sem excluir, respeitando a diversidade humana, presente em nosso dia a dia, considerando os diversos meios para aprendizagem e as múltiplas inteligências.

Estamos inseridos num mundo globalizado, em que todos somos capazes de aprender, considerando que cada um possui seu ritmo e subjetividade.

Sendo a educação inclusiva um processo de mudança estrutural que inclui: flexibilidade do currículo, acessibilidade de edifícios e instalações, adequação dos 
sistemas de comunicação oral e escrita, novos modelos de papel na escola comum, entre outras adaptações curriculares, estruturais e mobilidade.

Nas últimas décadas, uma nova ciência nasceu no entendimento de PRIGOGINE (1996), a física dos processos de desequilíbrio. Essa ciência revelou novos conceitos, como a auto-organização e estruturas dissipativas, amplamente usadas hoje em áreas que vão da cosmologia à ecologia e das ciências sociais à química e biologia. Presente quando o surgimento de uma atitude científica não se limita mais a situações simplistas e idealizadas, mas confronta o indivíduo com a complexidade do mundo real; o surgimento de uma ciência que permite que a criatividade humana se manifeste como a expressão singular de uma característica fundamental em todos os níveis da natureza.

\section{DESENVOLVIMENTO}

É fato que a sensibilidade humana presente varia marcadamente do início ao fim da Segunda Guerra Mundial e difere daquela que era percepção, reflexão e pensamento até a invenção da bomba atômica, o desenvolvimento da televisão e a formulação do novo pensamento científico que foi (e será) com Einstein na primeira década do século $X X$, e que lentamente penetrou na vida cotidiana.

Eventos como Hiroshima e Nagasaki, a Guerra Fria, a invasão soviética da Hungria, a Guerra do Vietnã, a revolta da juventude de 1968, a Primavera de Praga, o choque do petróleo, a queda do Muro de Berlim, a queda da ex-URSS e a inquietante ascensão do fundamentalismo religioso em todas as suas formas e variedades não podem mais ter a mesma sensibilidade humana e não pode mais ser estimulada ou influenciada por propostas que, de uma forma ou de outra, poderiam ser qualificadas de modernas.

Como resultado, novas formas de expressão musical surgiram (Beatles, Rolling Stones), novas formas de distribuição de imagens (MTV, CD-ROM), publicidade, grandes produções de filmes, o jornal mais dinâmico e com mensagens precisas (como Time Newsweek, Isto É, Veja, e adotaram novos formatos), novos modos estéticos e éticos que pouco ou nada têm em comum com o universo e as sensibilidades da época do romance balzaquiano, daquele a partir do qual a pintura, o cinema impressionista do começo. Mudanças expressivas na compreensão da 
moda, uma compreensão diferenciada das práticas sexuais em suas diversas variantes, o surgimento da AIDS, a Pandemia da COVID-19, que enfrentamos até os dias atuais, e que mudou e se encontra em mudança a maneira de transmitir o conhecimento, do professor ministrar aula. Todo esse conjunto denuncia o surgimento de outra realidade, uma nova era. Negar a evidência desses fatos para compreender a sociedade é negar a urgência de uma sensibilidade inteiramente nova.

Há uma necessidade urgente de mudar dos antigos para os novos paradigmas. Esse tempo de mudança pode ser chamado de princípio de princípios, como adverte MORIN (2000), ou seja, alguns termos magistrais comandam teorias sem ter consciência de si.

Atualmente se vive numa época em que temos um velho paradigma, um velho princípio que se obriga a separar, simplificar, reduzir, formalizar sem poder comunicar o descompasso e sem as quantidades ou complexidades da realidade para se poder compreender. Hoje, percebe-se um período entre dois mundos: um que está para morrer, mas ainda não morreu, e outro que quer nascer, mas ainda não nasceu. Vivese em uma grande confusão, em um daqueles períodos preocupantes de nascimentos que se assemelham aos tempos de hoje, de morrer.

Os desafios que se enfrenta hoje, segundo o autor, são a globalidade e a complexidade. Com efeito, a complexidade está presente quando os componentes que constituem um todo (como econômico, político, sociológico, psicológico, afetivo, mitológico), sendo indissociáveis, numa estrutura interdependente, interativa e retroativa das partes com o todo, e o todo com as partes. Os desenvolvimentos dos séculos passados e do presente, e da era planetária levam inevitavelmente e com mais frequência a um confronto com os desafios da complexidade.

CAPRA (1996) acrescenta que uma das características mais gratificantes da teoria dos sistemas emergentes é a nova compreensão da evolução que ela implica. Em vez de ver a evolução como resultado de mutações aleatórias e seleção natural, começa-se a reconhecer o desdobramento criativo da vida na forma de diversidade $e$ complexidade sempre crescentes como uma característica inerente de todos os sistemas vivos. Embora mutação e seleção natural ainda sejam reconhecidas como aspectos importantes da evolução biológica, segundo o autor o foco central está na criatividade, no desenvolvimento constante da vida em direção à novidade. 
Portanto, há complexidade onde quer que haja um emaranhado de ações, interações e feedback. E nada no universo está realmente isolado. Tudo está relacionado. Essa complexidade encontra-se no mundo da física e, embora de forma diferente, no mundo da filosofia, sociologia, política, pois vivemos na era planetária e tudo o que acontece em um ponto da terra pode ecoar em todos os outros. do planeta.

O mesmo fenômeno pode ser observado nas escolas como um todo. Apesar de todas essas transformações ocorridas nas últimas décadas, no entanto, continuase aprendendo a pensar analiticamente, a separar as partes do todo, sem considerar seu contexto e suas inter-relações. O pensamento ainda tem um caráter disjuntivo e redutor: tenta explicar um todo pela mera (re) constituição de suas partes. Em nome do imediatismo, se age constantemente tentando eliminar o problema da complexidade. Esse é um obstáculo, pois obedece à fixação de uma mentalidade que está gravada na mente do indivíduo desde a infância e desenvolvida na escola, implantada na universidade, ampliada e inserida nos programas de pós-graduação.

Reformando o pensamento, reformando o ensino, MORIN (2001), defende que é preciso apostar numa luta profundamente política e humana, no sentido de que se trata do futuro da humanidade. E se é verdade que a humanidade dispõe de recursos criativos inesgotáveis, então se antevê a esperança de uma educação para o terceiro milênio, que ao mesmo tempo transmite o antigo e se abre ao novo.

Esse novo cenário da ciência mudou e refletiu nos avanços da tecnologia, da informação e da comunicação, as novidades das ciências da vida, as pesquisas relacionadas ao cérebro humano, as profundas mudanças no cotidiano e a ameaça da exclusão social. Assim, os novos desafios que a educação enfrenta estão indo de assustadores a fascinantes.

Desta forma, os frutos da educação não devem mais se limitar ao conhecimento acumulado. É necessário e crucial tentar descobrir diferentes caminhos que podem dar lugar a novas aprendizagens.

É inegável que a quantidade excessiva de informações e sua transmissão acelerada pelos meios de comunicação afetam profundamente muitos aspectos do cotidiano que mudaram. Esse fator é um dos principais sinais e características do período histórico atual. Em toda a evolução da espécie humana, nunca houve mutações tão profundas e rápidas em um período tão curto. 
Para ASSMANN (1998): A revolução tecnológica em curso é irreversível nos seus aspectos básicos. Só não é irreversível - e se deve lutar para que não o seja - o manejo econômico-político no qual está inscrita atualmente. A questão é, pois, se a lógica da exclusão e a da sociedade da informação são inseparáveis ou se a sua coincidência se deve apenas ao predomínio atual da lógica do mercado.

Não se pode negar que a sociedade da informação é o resultado de grandes transformações em curso por meio das tecnologias da informação e não um mero fato tecnológico que deve ser separado das formas políticas e econômicas de organização das sociedades.

Os envolvidos no processo acabam por ser desafiados e tentam repensar a cada estudo o que eles realmente significam e que impacto essas transformações, que se chamam de desenvolvimento, têm (1). O problema histórico e sociológico que se coloca neste contexto é saber como uma nova sociedade com velhos emerge e se reformula.

O que aconteceu e continua a acontecer com a educação com base nesta estrutura atual? O que significa educação hoje? O que pertence à escola, à educação, a cada um de nós no mundo de hoje? Quais são as diferenças entre o antigo e o novo paradigma educacional?

Diante do exposto, como negar que as ciências da educação precisam de uma revolução, de uma reformulação intensa? Acredita-se que sejam muitas décadas de atraso que precisam ser restauradas. Mesmo que se arrependa de que a pedagogia era praticada de forma mais adequada na Grécia antiga do que é hoje e que mesmo com o Renascimento não recuperou a capacidade de educar, pode-se ver que a escola deve ser antes de tudo a escola e precisa de um lugar de permanente e para ser um desenvolvimento contínuo. O que se presencia no decorrer da aprendizagem e do amadurecimento do estudante não é apenas o aspecto cognitivo, mas um indivíduo em constante processo de descoberta.

Já não é novidade que o principal alvo das críticas progressistas às instituições nacionais na última década tem sido a escola. Durante o mesmo período, tornou-se visível e evidente que as instituições educacionais não são os instrumentos da democracia e da igualdade com que muitos sonharam. Essa crítica foi salutar de muitas maneiras, pois ajudou a aumentar a conscientização sobre o importante papel que as escolas - e o currículo explícito e o currículo oculto (2) - desempenham na 
reprodução de uma sociedade estratificada que os mantém notavelmente inofensivos de classe, gênero e corrida. Até porque se sabe até que ponto o sistema cultural e educacional é um elemento determinante na manutenção das relações de dominação e exploração nessas sociedades.

Em busca de respostas às reclamações das escolas é de que as instituições não correspondem às reais necessidades dos seus alunos, é necessário analisá-las sob diferentes perspectivas: sociedade, escola, estudantes e professores. A primeira perspectiva é a mais abrangente e influencia as demais, não se pode descuidar da relação entre a produção escolar e as reais oportunidades que a sociedade oferece às diversas classes sociais. Muitas vezes, os alunos de baixa renda são classificados como deficientes mentais, com problemas de aprendizagem e/ou comportamentais, mas na realidade, carecem de oportunidades de crescimento cultural, construção cognitiva e desenvolvimento da linguagem, condições dignas de sobrevivência, fatores responsáveis pelo aumento das oportunidades educacionais. Com esse conjunto de influências, não se pode deixar de mencionar que a formação e a personalidade do profissional afetam significativamente o processo de atuação do aluno.

Portanto, o sistema educacional, exatamente por estar inserido em uma rede mais ampla de relações sociais, pode representar um terreno importante e fértil, no qual provavelmente ações significativas podem ser desenvolvidas.

No século XIX, a sociedade industrial se concentrava mais na produção e nas relações de trabalho. Essa realidade de submissão da educação em favor de outros interesses parecia ter se intensificado ao longo do último século, quando as escolas muitas vezes mostravam uma forte sensação de serem ultrapassadas pelos meios de comunicação de massa, principalmente a televisão.

A educação clássica apresentava nos seus princípios fundamentais e fortemente integrados, a vontade de libertar a criança e, graças ao seu próprio potencial laboral, conduzi-la ao mundo superior da razão e do saber, da afirmação do valor universal, da cultura ou mesmo da comunidade em que a Criança vivia com o implícito duplo esforço de libertação da tradição e ascensão a valores intimamente relacionados com a hierarquia social.

Observa-se que por parte dos dias atuais a educação em geral e a área curricular em particular têm-se dedicado grande energia à prossecução de um objetivo 
específico: um conjunto geral de princípios para orientar a imagem para gerir o planeamento e a avaliação. A maior parte do trabalho foi reduzida a tentativas de desenvolver o método e a técnica mais eficientes no desenvolvimento do currículo.

Embora algumas mudanças tenham sido feitas nas instituições educacionais, ainda há um problema fundamental que precisa ser tratado com seriedade e honestidade, a forma natural pela qual os sistemas de dominação e exploração persistem e se reproduzem sem serem conscientemente reconhecidos pelos envolvidos. Este aspecto é único e vital na educação, que se apresenta como uma área onde as práticas geralmente aceitas devem procurar ajudar e motivar os alunos a resolver alguns dos problemas sociais e educacionais que enfrentam. No entanto, as instituições escolares continuam a ignorar algo que se tornou bastante claro na literatura sociológica recente.

Escolas, segundo APPLE (1989), não são apenas instituições de reprodução, são instituições nas quais o conhecimento explícito e implícito transforma os alunos em seres passivos, capazes e ávidos de se adaptarem a uma sociedade injusta. Essa interpretação é falha em dois aspectos. Primeiro, ela vê os alunos como internalizadores passivos de mensagens sociais predefinidas. Tudo o que é veiculado pela instituição, seja no currículo formal ou no currículo oculto, é absorvido sem qualquer alteração devido as culturas de classe ou a rejeição das mensagens sociais dominantes pela classe dominada.

Assim, como a escola está envolvida em paradoxos, as ideologias também estão repletas de antítese, porque não se constituem nas crenças atuais. Pode até ser errôneo pensar nisso apenas como um sistema de crenças, mas em conjuntos de significados vividos, de práticas e relações sociais que costumam ser internamente contraditórias. Com componentes internos, aos quais evidenciam as causas da desigualdade na sociedade, enquanto tendem a reproduzir os significados e as relações ideológicas que mantêm a hegemonia das classes dominantes. Por esta razão, as ideologias são disputadas, origem perpétua de lutas constantes.

A partir desta e de outras descobertas, fica claro que a sociedade em que se vive não tem de devir, existir.

A lógica da exclusão se enraizou nas instituições do mundo de hoje e às vezes se manifestou naturalmente. Portanto, o difícil desafio para os homens continua sendo a criação de órgãos públicos que apoiem e promovam as conversões individuais e o 
consenso sobre justiça social. Nesse sentido, a educação solidária se anuncia como a mais progressista e exigente tarefa social emancipatória.

A educação é, portanto, exigida em que todos os alunos, indiscriminadamente, independentemente do fato de terem dificuldades ou não, tenham acesso à escola.

Se você pensa em educação, é importante criar alternativas pedagógicas, técnico-pedagógicas, psicopedagógicas e sociais que possam contribuir no processo de aprendizagem de todos os estudantes, no entanto, a teoria nem sempre anda de mãos dadas com a prática. Os especialistas, profissionais da educação, principalmente os professores, muitas vezes se sentem sozinhos nessa busca por parâmetros e subsídios para sua prática diária.

O discurso é recorrente, mas quando se pensa em educação inclusiva, é importante lembrar que o homem é fruto do ato de transformar e adaptar à realidade da realidade, a capacidade em transformar a si mesmo. A partir disso, conclui-se que a educação é um processo que possibilita ao homem tornar-se sujeito de suas próprias ações em harmonia consigo mesmo e não apenas como objeto de outros sujeitos. Este é o caminho e o meio para que as pessoas se construam como seres inerentes ao mundo globalizado, pertencente a uma sociedade justa, igualitária e participativa.

Da compreensão de inúmeros aspectos relacionados aos conceitos de igualdade e diferença, é possível investir em pessoas melhores e mais fraternas, levando a profundas mudanças na educação.

No entanto, a verdadeira inclusão, baseada nos princípios da justiça, é conhecida como um processo demorado porque é a consciência de requerer a mudança de paradigmas antigos para novos. Algumas mudanças educacionais mostram sinais de progresso. Os primeiros frutos dessa conquista já são visíveis, com a tentativa de incluir os alunos com necessidades educacionais especiais no ensino regular.

Escusado será dizer que as dificuldades são muitas: as barreiras e limitações dos profissionais, envolvimento no trabalho, são facilmente percebidas. Essas dificuldades não se limitam à formação do corpo técnico da escola, mas a todo um contexto de fazer da educação um direito de pensar e realmente ver como um direito de todos. 
Neste contexto, não é difícil constatar que as atitudes dos responsáveis pelos alunos assumem uma importância fundamental e constituem uma condição indispensável para uma consciência cada vez maior da educação e do desenvolvimento humano.

O estabelecimento escolar deve efetivamente estar mais voltado para as especificidades dos alunos do que para as necessidades da sociedade. Deve-se dar especial importância as habilidades dos alunos para se expressar, seja oralmente, por gestos, desenhos ou escrito, compreendendo as mensagens e relação interpessoais necessárias ao desenvolvimento humano. O objetivo é ensinar os estudantes a se relacionar, se inserir nu mundo em que vivemos, a decifrar todas as linguagens da sociedade, do planejamento urbano, das atividades administrativas as da pesquisa científica e tecnológica, compreender a leitura dos meios de comunicação de massa, especialmente a televisão e internet, mas também insistir na própria comunicação intercultural.

Para um diploma escolar, se faz necessário questionar pensamentos, conceitos e sentimentos, o seu significado e contextualizar a tão comentada crise dos paradigmas atuais. Parece muito mais amplo do que se pensava inicialmente: uma crise de confiança no poder, uma crise no desenvolvimento de valores, processos, práticas e modelos de emancipação, crise política ou mesmo uma crise do imaginário social como um todo.

É necessário romper com antigos paradigmas e definições vagas ou superficiais para uma perspectiva que nos permita ver que a sociedade é capaz de criar coletivamente mais do que meras representações e imagens, mecanismos e meios de emancipação. Só assim é possível ir para uma escola que oportunize uma educação de qualidade a todos.

Os objetivos e expectativas que alimentaram a escola até o presente momento podem levar ao abandono de mais de um passado. Saber disso ajuda a investir nas medidas atuais em função das necessidades divulgadas. Pense na escola como VALLE (1997):

É preciso ver a escola como instituição do político e sua crise como espelho da crise da vida pública e dos becos sem saída da realidade social. Quanto às instituições imaginárias, a tarefa de reconstruir é constante, sempre urgente e oportuna. No caso específico da escola, ainda há muito a ser feito: é preciso desenvolver as análises mais amplas, os fundamentos da educação brasileira; volte no tempo e busque 0 apoio de disciplinas cuja contribuição para a educação não foi devidamente explorada. Chega-se assim à cozinha do quotidiano, à sala de aula, 
aos métodos, processos e às relações que se estabelecem entre nós e a escola. Esse é o programa e o desafio.

Olhando para a escola numa perspectiva diferente dos demais, pode-se ver o passado como um trampolim para o futuro a ser dado ao indivíduo e à sociedade. Por que os estudantes aprendem? Como aprendem? Com que propósito ocorre a aprendizagem? Quando aprendem? Por que alguns estudantes possuem alguma dificuldade para aprender? Qual é a relação entre interesse, conhecimento, e o desenvolvimento do ser? Será que o aprender de hoje é conhecimento para o futuro?

É preciso conhecer a escola e torná-la um espaço educativo para a era das relações.

\section{CONSIDERAÇÕES FINAIS}

Fica claro, portanto, que todas as mudanças que o mundo viveu nas últimas décadas e atualmente, estão nos mostrando uma realidade diferente, com mais sensibilidade para entender o mundo.

Tudo o que acontece depende do mundo em que se vive junto e se tem que estar sempre pronto para desenvolver a criatividade e criticidade. E na escola não pode ser diferente, é preciso levar em conta o contexto e suas conexões para desenvolver o pensamento. Desta forma entende-se que o desenvolvimento do pensamento é necessário para construção da aprendizagem. Portanto, o educador precisa associar o antigo com visões sobre o novo.

Diante das descobertas da ciência, do avanço tecnológico e das ameaças de exclusão, a escola enfrenta desafios sobre os novos caminhos que o educador tem que seguir para chegar as novas aprendizagens.

O grande processo evolutivo em que o mundo está envolvido é fruto dos avanços tecnológicos das tecnologias de informação e comunicação, e é nesse contexto que se faz necessário refletir sobre a atual educação.

Hoje existe um grande esforço educacional, principalmente no que diz respeito ao currículo, princípios que norteiam o planejamento e a avaliação educacional. É importante criar alternativas educacionais e sociais que possam contribuir para o processo de aprendizagem de todas os estudantes. 
Nesse sentido, a escola deve em todos os aspectos ser mais bem adaptada à vida de seus estudantes, tendo como objetivo uma compreensão prévia do que ele traz consigo para ajudá-lo a adquirir novos conhecimentos.

Entende-se que precisa das inovações na área educacional para que ocorra mudanças significativas na sociedade. Sabe-se que as condições externas e internas surgem por meio do aprendizado, são aspectos da realização dessa relação homemsociedade.

A partir deste estudo, nota-se que existem vários aspectos e obstáculos associados à realização da verdadeira inclusão escolar, sendo necessário investir na educação, proporcionando assim, uma ESCOLA PARA TODOS.

\section{BIBLIOGRAFIA}

APPLE, Michael. Educação e poder. Porto alegre: Artes Médicas, 1989

ASSMANN, Hugo. Reencantar a educação: rumo a uma sociedade aprendente. 2. . ed. Petrópolis: Vozes, 1998.

CAPRA, Fritjof. A teia da vida: uma nova compreensão científica dos sistemas vivos. São Paulo: Cultrix, 1996.

MORIN, Edgar. Os sete saberes necessários à educação do futuro. São Paulo: Cortez, 2000.

A cabeça bem-feita: repensar a reforma, reformar o pensamento. 3 . ed. Rio de Janeiro: Bertrand Brasil, 2001.

PRIGOGINE, llya. O fim das certezas: tempo, caos e as leis da natureza. São Paulo: Unesp, 1996.

VALLE, Lílian do. A escola imaginária. Rio de Janeiro: DP\&A, 1997.

\section{NOTAS:}

1 Desenvolvimento, nesse contexto, refere-se ao empreendimento que se faz com objetivo de passar de um tipo de sociedade para outro.

2 Sobre currículo, ver Silva (1999). Nessa obra, o autor propõe-se a traçar um mapa dos estudos sobre currículo, desde sua gênese, nos anos de 1920, até as atuais pós-críticas.

3 Assmann (1998, p.28) destaca as transformações, no mundo de hoje, devemse a três choques básicos ressaltados nos abundantes documentos oficiais da União europeia: o choque da mundialização e o choque da civilização científica e técnica. 